\title{
The indirect effect of a focus group for psoriatic patients on their caregivers
}

\author{
Antonella Demma, ${ }^{1}$ Caterina Suitner, ${ }^{2}$ Emilia Ferruzza, ${ }^{2}$ Chiara Nicolini, ${ }^{3}$ Massimo Donini ${ }^{4}$ \\ ${ }^{1}$ Aetos, Scuola di Specializzazione in Psicoterapia, Venezia; ${ }^{2}$ Department of Psychology of Development and Socialization, University \\ of Padova, Padova; ${ }^{3}$ S.I.P.P., Società Italiana di Psicoterapia Psicoanalitica, Milano; ${ }^{4}$ Operative Unit of Dermatology, Ulss 3 Serenissima, \\ Venezia, Italy
}

Correspondence: Antonella Demma, Aetos, Scuola di Specializzazione in Psicoterapia, Via Silvio Trentin, 42, 30171 Venezia, Italy. E-mail: antonella.demma@ordinepsicologiveneto.it

Citation: Demma, A., Suitner, C., Ferruzza, E., Nicolini, C., \& Donini, M. (2021). The indirect effect of a focus group for psoriatic patients on their caregivers. Research in Psychotherapy: Psychopathology, Process and Outcome, 24(1), 14-21. doi: 10.4081/ripppo.2021.486

Acknowledgments: Dermatologists for the heart, 'In-Group' Project, 2015 .

Funding: study realized with the support of La Roche-Posay.

Contributions: AD made substantial contributions to the design and clinical implementation of the work, made contributions to the interpretation of the data, drew up and revised the manuscript for important intellectual content; CS made substantial contributions to analyses, interpretation of data and to the writing of the manuscript; EF made substantial contributions to the design of the work and interpretation of data, drew up and revised the manuscript for important intellectual content; $\mathrm{CN}$ made substantial contributions to the design of the work and interpretation of data, drew up and revised the manuscript for important intellectual content; MD made data collection possible by hosting the study in his hospital; he also provided data about health conditions of patients

Conflict of interests: the authors declare no potential conflict of interests.

Availability of data and materials: data - according to ethical approval of the study protocol - cannot be made accessible through a public repository. However, data are available upon request for researchers who consent to adhering to the ethical regulations for confidential data.

Ethical approval: all procedures performed in studies involving human participants were in accordance with the ethical standards of the institutional and/or national research committee and with the 1964 Helsinki Declaration and its later amendments or comparable ethical standards.

Informed consent: written informed consent was obtained from all individual participants included in the study.

Received for publication: 1 August 2020.

Revision received: 3 November 2020.

Accepted for publication: 29 December 2020.

This work is licensed under a Creative Commons Attribution NonCommercial 4.0 License (CC BY-NC 4.0).

${ }^{\circ}$ Copyright: the Author(s), 2021

Licensee PAGEPress, Italy

Research in Psychotherapy:

Psychopathology, Process and Outcome 2021; 24:14-21

doi:10.4081/ripppo.2021.486

\begin{abstract}
Psoriasis is a chronic skin disease involving not only epidermic damages but also psychological distress for patients and their family caregivers. Little is known about the effects of a psychological support for psoriatic patients on their caregivers' well-being. The goal of the present study was to investigate the indirect effects of the participation in a dynamic focus group reserved for psoriatic patients on their caregivers in terms of quality of life. The study involved 52 psoriatic patients and 41 family caregivers. Patients' wellbeing was assessed using the dermatology quality of life index, hospital anxiety and depression scale. The impact of the disease on caregivers was assessed using the family dermatology life quality index (FDLQI). Data were analyzed with linear mixed models. The caregivers of psoriatic patients involved in the psychodynamic focus group reported levels of FDLQI that decreased over time, therefore showing an improvement in their quality of life in relation to the pathology of their relatives; the caregivers of patients who did not participate in the psychodynamic focus group, instead, had levels of FDLQI that were stable over time. The results provide preliminary evidence that the group setting of the Psychodynamic Focus Group may alleviate the negative impact of psychosomatic disease on the caregivers.
\end{abstract}

Key words: Psoriasis; psychodynamic focus group; family caregiver; family dermatology life quality index.

\section{Introduction}

Psoriasis is an inflammatory skin disease characterized by reddened and scaling skin rashes with a chronic relapsing course (Michalek, Loring, \& John, 2017). This disease affects $2-4 \%$ of the general population in the world, mainly Caucasian people, with no gender differences. People with family history of psoriasis show prevalence of early onset activation. There are several clinical variants of the disease (Nestle, Kaplan, \& Barker, 2009), namely forms limited to certain areas of the body (elbows, knees, back, and scalp); forms affecting almost the entire body surface (erythroderma desquamative); forms affecting the joints (psoriatic arthritis). Numerous studies (Ak et al., 2012; Connor, Liu, \& Fiedorowicz, 2015; MartinBrufau et al., 2015) theorize a link between genetics and psychological factors in both the etiology and the development of the disease. Patients are characterized by stress susceptibility (Remröd, Sjöström, \& Svensson, 2015); indeed, stressful events are among the main environmental 
factors for the pathogenesis of this disease (Manolache, Petrescu-Seceleanu, \& Benea, 2010; Zeng, Luo, Huang, $\& \mathrm{Lu}, 2017)$. The psychological literature describes psoriatic patients as characterized by: i) negative and submissive emotions, which are in turn positively correlated with the extent of the lesions (Martín-Brufau et al., 2015); ii) feelings of anxiety and depression (Chamoun, Goudetsidis, Poot, Bourdeaud'hui, \& Titeca, 2015; Connor et al., 2015); iii) lack of assertiveness and mistrust (Remröd et al., 2015), social inhibition (Molina-Leyva, Caparros-delMoral, Ruiz-Carrascosa, Naranjo-Sintes, \& JimenezMoleon, 2015).

The literature has mainly focused on the impact of the disease on the quality of life (QoL) of patients (Petraškienė, Valiukevičienè, \& Macijauskienè, 2016). Studies have highlighted stigmatization effects (Fortune, Richards, Main, \& Griffiths, 2000), a feeling that people with psoriasis experience independently of the clinical features of the disease (lesion visibility or extension). Moreover, decreased self-esteem among psoriatic patients is often linked to the impossibility to perform daily tasks due to psoriatic lesions (Sobell et al., 2016). Importantly, the psychological consequences are evident also at the interpersonal level, as patients report difficulties in interpersonal relationships due to the disease visibility (Molina-Leyva et al., 2015; Remröd et al., 2015). It is therefore clear that indirect effects of such illness may impact also those who are involved in caring activities for the patients. In literature, numerous studies highlighted the experience of caregivers of patients suffering from chronic diseases and in need of psychological support (Grapsa et al., 2014; Kross, 2015).

In the case of psoriasis, most research focuses on the pediatric field. The psoriasis of children and adolescents can in fact worsen the quality of life of family members even in the presence of mild illness (Lin, 2012; Salman, Yucelten, Sarac E, Saricam, Perdahli-Fis, 2018). QoL's impairment may also be associated with psychosocial comorbidity and emotional disorders (Dorneless da Silva Manzoni et al., 2013; Salman et al., 2018). A combined approach between medical therapy, family support and quality of life assessment can therefore be particularly useful for the patients' caregivers (Salman et al., 2018). The quality of life of caregivers of adult patients with psoriasis can also be affected by the disease severity (Eghlileb, Davies, \& Finlay, 2007; Tadros et al., 2011). Because of the nature of psoriasis, immediate family members are often involved in caregiving and are affected in many ways by the patient's skin condition (Basra et al., 2008). Tadros et al. (2011) highlighted the positive correlation between the patient's QoL score [dermatology life quality index (DLQI)] and the parents' QoL score [family dermatology life quality index (FDLQI)]. Importantly, the severity of psoriasis has both a direct impact on the patients' quality of life and an indirect impact on caregivers' quality of life (Tadros et al., 2011).
From the literature, it is therefore clear that psoriatic patients need psychological support, and that caregivers are affected by the psychological consequences of the patients' disease - elements that doctors should take into account by managing the patients' health not only focusing on the disease, but also caring about the entire affective ground in which the patients are embedded (Eghlileb et al., 2007). Moving a step forward, we here wonder whether psychological support to patients may have indirect and/or direct effects, and be eventually beneficial for the caregivers. An indirect effect can be expected in the sense that the positive outcomes of a psychological support may spread from patients to caregivers, in a sort of domino effect. Accordingly, research on the impact of psoriasis on family members highlights that anxiety levels of psoriatic patients affects - in a unidirectional way caregivers more than the severity of the disease itself (Richards, Chong, Mason, \& Griffiths, 2002; Eghlileb et al., 2007). From this perspective, the psychological support is thought to have an indirect effect, with an initial impact on patients that, in turn, spreads to caregivers.

A direct effect can also be expected. Specifically, the effect of the psychological support may be beneficial for caregivers independently from its effect on patients. Arguably, the impact of the disease on caregivers may derive from the unshared responsibility the caregiver experiences, linked to the lack of control and feelings of helplessness, common among caregivers (Basra \& Finlay, 2007). This responsibility may be alleviated from the participation of their cared ones in a psychological group. The psychological support may therefore directly affect caregivers by reducing the weight of their responsibility. Under this perspective, the psychological support to patients turns into a direct benefit for their family members, which are alleviated from the worries associated with the disease.

In this study, we therefore consider the disease within the affective network of the involved persons. In particular, the theoretical grounding of the study is the relational approach that considers patients in their interdependence with their family or caregivers (Goldberg \& Richler, 2011). According to this theoretical perspective, the well-being or discomfort of one member turns into the well-being or discomfort of the whole family (i.e., indirect effect). Moreover, the caregivers are possibly affected by their role of support provider. Being the helper of a sick person implies psychological duties and preoccupation, which may directly affect the quality of life. When the person in need is provided with an external and independent support, the caregiver's charge is alleviated (Del-Pino-Casado, FríasOsuna, Palomino-Moral, Ruzafa-Martínez, \& Ramos-Morcillo, 2018). In this way the psychological support to the patients may have a direct effect on caregivers.

The goal of the present study is therefore explorative, and we aim at investigating the direct or indirect effects for family members of a psychodynamic support to patients. 


\section{Methods}

\section{Participants}

The study involved 80 psoriatic patients, and one caregiver each - for a total of 160 contacted people (age range 18-75). They were all Caucasian and residents in North Italy. Participants that did not complete the entire questionnaire in all 3 administrations or that participated in less than 4 focus group sessions were excluded from the analyses. The experimental group was composed of $28 \mathrm{el}-$ igible patients: 18 males, 10 females, age mean $(M)=59.31$, standard deviation $(S D)=10.73,21.4 \%$ suffered from mild psoriasis, $50 \%$ were affected by moderate psoriasis, $28.6 \%$ suffered from severe psoriasis. $85.8 \%$ reported to have a stable emotional bond, $14.2 \%$ declared to be single. The level of education consisted of $46.4 \%$ primary school/middle school, $21.4 \%$ high school, $32.2 \%$ graduation. Eighteen patients reported to have other family members suffering from psoriasis. Their corresponding caregivers were 22 ( 8 males, 14 females, age $M=57.18$, $\mathrm{SD}=7.27): 86.3 \%$ were relatives/cohabitants, 13.7 were friends/brothers-sisters. The caregivers' level of education consisted of $41 \%$ primary/middle school, $45.4 \%$ high school, $13.5 \%$ graduation.

The control group was composed of 24 eligible patients (13 males, 11 females, age $\mathrm{M}=53.5, \mathrm{SD}=15.44)$ : $29.1 \%$ suffered from mild psoriasis, $62.5 \%$ were affected by moderate psoriasis, $8.4 \%$ suffered from severe psoriasis; $62.5 \%$ had a stable emotional bond, $37.5 \%$ were single. The level of education consisted of: $33.3 \%$ primary school/middle school, $41.6 \%$ high school, $25.1 \%$ graduation. Sixteen patients had other cases of psoriasis among family members. Their corresponding caregivers were 19 (11 males, 8 females, age: $\mathrm{M}=56.89, \mathrm{SD}=12.11$ ): $89,4 \%$ were relatives/cohabitants, $10.5 \%$ were friends/brotherssisters . The level of caregivers' education consisted of: $52.6 \%$ primary/middle school, $15.9 \%$ high school, $31.5 \%$ graduation.

All caregivers declared that they were actively involved in the management of the patients' psoriatic pathology.

\section{Instruments}

Self-report questionnaires for both patients and caregivers were collected during the initial screening (T1), after three months (end of the meetings, T2) and at the follow-up to six months (T3).

The assessment of families was carried out using a self-report 10-items questionnaire Family Dermatology Life Quality Index-FDLQI (Basra, Fenech, Gatt, Salek, \& Finlay, 2008) in its Italian validation (Sampogna et al., 2013), evaluating the impact that skin disease had had, in the previous 4 weeks, on the caregivers' quality of life. It is a questionnaire addressed to adult family members or partners of patients with skin diseases.
The families' well-being linked to skin pathology was investigated with questions regarding emotional stress, physical well-being, interpersonal relationships, social life, leisure time, and the impact the pathology had on economic, working and daily tasks. Each question scored from 'not at all' to 'very much' (not at all=0; a little=1; quite a lot $=2$; very $\operatorname{much}=3$ ). The higher the score, the more the quality of life is impaired. The maximum possible score is 30 . The questionnaire is structured to be used alone or in combination with other questionnaires such as the DLQI.

The scale proved to be highly reliable across administration times in the Cronbach's test $\left(\alpha_{\mathrm{T} 1}=0.75 ; \alpha_{\mathrm{T} 2}=0.82\right.$, $\alpha_{\mathrm{T} 3}=0.89$ ).

Patients were asked to complete three self-administered questionnaires:

- DLQI, (Chronbach's $\left.\alpha_{\mathrm{T} 1}=0.83, \alpha_{\mathrm{T} 2}=0.86, \alpha_{\mathrm{T} 3}=0.83\right)$ in its Italian validation (originally by Finlay \& Khan, 1994; Baranzoni et al., 2007). There are 10 questions, focused on the following topics: symptoms, embarrassment, shopping and home care, clothes, social and leisure, sport, work or study, close relationships, sex, treatment. Each question refers to the impact of the skin disease on the patient's life. Each question is scored from 0 (not at all) to 3 (very much) and refers to the impact of the skin disease on the patient's life during the previous week. The final score is computed by summing each item score and therefore ranges from 0 (no impact of skin disease on quality of life) to 30 (maximum impact on quality of life).

- Hospital anxiety and depression scale (HADS) (originally by Zigmond \& Snaith, 1983) in its Italian validation (Costantini et al., 1999), which is composed of 14 items, 7 relating to anxiety and 7 to depression. Each item of the questionnaire is assessed on a 0-3 points scale, with a resulting score ranging from 0 and 21 for both anxiety (Chronbach's $\alpha_{\mathrm{T} 1}=0.71, \alpha_{\mathrm{T} 2}=0.80$, $\alpha_{\mathrm{T} 3}=0.81$ ) and depression (Chrombach's $\alpha_{\mathrm{T} 1}=0.50$; $\alpha_{\mathrm{T} 2}=0.54 ; \alpha_{\mathrm{T} 3}=0.66$ ).

- Medication adherence questionnaire (MAQ), also known as the 4-item Morisky medication adherence scale and Morisky scale by Morisky, Green and Levin (1986), in its Italian validation (Fabbrini et al., 2013), consisting of 7 forced-choice questions (Yes or $\mathrm{No}$ ) that establish adherence to therapy.

The disease severity was assessed by a dermatologist using the psoriasis area severity index (PASI) (Kreft, Kreft, Resman, Marko, \& Kreft, 2006). This index analyses four body regions (trunk-30\%, head-10\%, upper-20\% and lower- $40 \%$ limbs) in relation to Erythema, Thickness, Desquamation of the plaques. Each of these areas is separately scored and the four scores are then combined into the final PASI. The result of the PASI may vary from 0 to 72 (Kreft et al., 2006). Absolute PASI score is often used to define entry into a trial and is used to assess response to treatment that is important to measure efficacy and out- 
comes (Feldman et al., 1996). PASI data were coded during the initial screening, after three months (end of the meetings) and during follow-up to three months.

\section{Procedure}

This study was part of the 'In-group' project that took place within the Department of Dermatology of the Hospitals of Venice (Italy) and Mestre (Italy) and was ethically approved by the hospital head physician.

Participation in the study was voluntary for both patients and caregivers. Caregivers' non-participation did not determine the patient's exclusion from the study, but vice-versa the non-participation of patients resulted in the exclusion of their carer from the experimental group.

The patients included in the medical records of the hospital database were assigned to one of the two groups (i.e., experimental or control). The procedure was established to follow the filing order of the medical records, assigning them alternatively either to the experimental group or to the control group. The investigators were not blind to the procedure. The recruiting procedure, therefore, involved a first phone contact in which patients were invited to a face-to-face interview with the psychotherapist. Participants were required to be capable of consent, to be cooperative and motivated. During the interview the purpose and the mode of implementation of the project were explained, and probed motivation was assessed.

Patients assigned to the experimental group were offered to participate in six fortnights focus groups for three months, each session lasting an hour and a half. Moreover, they were asked to fill in the questionnaires. Group composition (seven to ten participants) was stable over time and focused on the development of affective experiences related to the disease.

Patients assigned to the control group were offered to fill in the questionnaire.

Patients who refused to participate in the psychological intervention were excluded from the study. After signing the informed consent, each patient of any group was given instructions on how to participate in the study. Each patient was invited to meet the dermatologist for an evaluation of the current pathological situation (unless updated data were already available). The battery of questionnaires and a medical history sheet was administered to each patient. Each participant freely identified a carer (e.g., a family member or a close acquaintance) among people that closely and actively participated in the management of their psoriatic disease. The caregivers received the informed consent form, a medical history form and FDLQI questionnaire. They were free to participate in the study by self-completing the provided material.

The group work was designed to promote the experience of some of the non-specific therapeutic factors as described by Yalom and Leszcz (2005). In particular, group cohesion, the universalization of the problem and 'he personal support - which is the possibility for the patients to share with others the status of their own illness and receive support - and the altruism - which is the possibility of experiencing one's ability to help others and information which consists in receiving clarifications on one's own problems.

Furthermore, time limit and fortnightly meetings can promote an increased work rate and reduce the risk of an exaggerated cohesion and fusion within the group, which is typical of homogeneous groups (Mackenzie, 1995). Each group was conducted together by a psychotherapist and a dermatologist. Both the psychotherapist and the dermatologist were the same for all groups. The dermatologist, who had neither psychological training nor previous group experience, provided information on the disease, according to one of the non-specific therapeutic previously mentioned (Yalom \& Leszcz, 2005). The presence of the psychotherapist and the dermatologist thus favored an integrated approach between mind and body.

Patients assigned to the control group were invited to participate in three data collections scheduled in line with the experimental group. In the case of consent to participation - after signing the informed consent providing information about the processing of medical records and agreeing to participating in the study - participants were given the standardized battery of self-report questionnaires. Similarly, in the experimental group each patient was provided with a sealed envelope to be given to one caregiver. Materials and procedure were the same for the experimental and the control group, except the participation in the Focus Group. The psychotherapist was one of the investigators.

\section{Results}

Using the JMP ${ }^{\circledR}$ software (Version 14. SAS Institute Inc., Cary, NC, 1989-2019), we run a full factorial linear model on the FDLQI with participants and psychodynamic group included as random effect, group (2-levels) and time of data collection (3-levels) as factors. From the analyses, it emerged an interaction between psychodynamic groups and time of data collection, $F(2,78)=3.22$, $\mathrm{P}=0.04$. As shown in Figure 1 and Table 1, caregivers of patients participating in the psychodynamic group reported levels of FDLQI that decreased over time, whereas for the control group caregivers scores increased over time. In particular, the FDLQI at $\mathrm{T} 1(\mathrm{M}=3.89, \mathrm{SD}=3.33)$ is higher than at the final stage, $\mathrm{T} 3(\mathrm{M}=2.23, \mathrm{SD}=2.64)$, Cohen's $\mathrm{d}=1.18$. If we include in the model the psychological scores of the patients (i.e., depression, anxiety and quality of life), the effect remains significant, $F(2$, $78)=3.08, P=0.05$, suggesting that the effect of the therapy is by itself beneficial to the caregivers, rather than having a mediated effect through the patients' well-being. Indeed, the participation in the focus group failed to bring immediate benefit to the patients' well-being in terms of depression, anxiety and quality of life (see below), possibly 
suggesting the need for the patients for a more intense intervention.

The effect of focus group participation and patients' psychological well-being was investigated through fullfactorial linear models (two-tailed) using the software JMP, with group (2-levels) and time of data collection (3levels nested in participants) as factors. Four separate models were run using as dependent variables anxiety, depression, DLQI, and PASI scores (Tables 1 and 2). Regarding anxiety, the experimental group $(\mathrm{M}=6.18$, $\mathrm{SD}=3.44)$ was characterized by higher anxiety scores compared to the control $(\mathrm{M}=4.18 ; \mathrm{SD}=3.08), F(2$, $100)=6.78, \mathrm{P}=0.01$. This difference was not modified by administration time. Depression and DLQI scores were not affected by group nor administration time. PASI scores were decreasing over time, confirming the effects of the therapies provided by the hospital $(F(2,100)=6.23$, $\mathrm{P}=0.002$ ), but this effect was not moderated by participation in the group.

\section{Discussion}

Previous cognitive studies on psoriatic disease focused on patients as isolated individuals (Kabat-Zinn et al., 1998; Fortune et al., 2000; Bundy, Pinder, Bucci, Reeves, Griffiths, \& Tarrier, 2013; Schwartz, Evers, Bundy, \&
Kimball, 2016), neglecting the effect of patients' psychological support on their family members. Changing the perspective, we here experimentally investigated the psy-

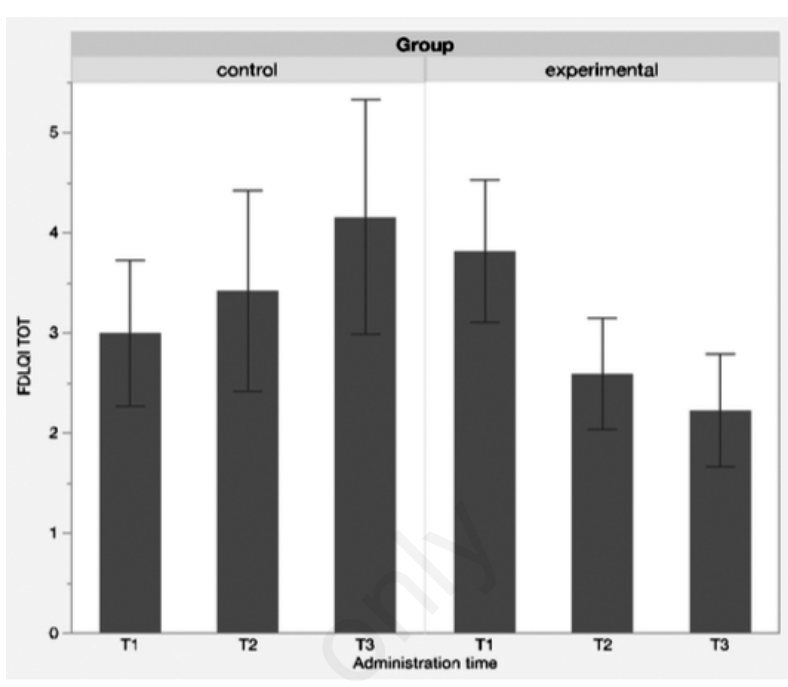

Figure 1. Caregivers' quality of life [family dermatology life quality index (FDLQI)] according to administration time (T1, initial screening; T2, end of therapy; T3, follow-up) and patients' participation in psycho-dynamic (experimental) group or not (control group).

Table 1. Means and standard deviations of anxiety, depression, family dermatology life quality index and psoriasis area severity index scores of control group and experimental group's participants across the three data collections.

\begin{tabular}{|c|c|c|c|c|c|c|c|}
\hline & & \multicolumn{3}{|c|}{ Control group } & \multicolumn{3}{|c|}{ Experimental group } \\
\hline & & T1 & $\mathrm{T} 2$ & T3 & T1 & $\mathrm{T} 2$ & T3 \\
\hline \multirow[t]{2}{*}{ FDLQI } & M & $3.00^{\mathrm{ab}}$ & $3.42^{\mathrm{ab}}$ & $4.16^{\mathrm{ab}}$ & $3.82^{\mathrm{a}}$ & $2.59^{\mathrm{ab}}$ & $2.23^{\mathrm{b}}$ \\
\hline & $\mathrm{SD}$ & 3.18 & 4.36 & 5.11 & 3.33 & 2.61 & 2.64 \\
\hline \multirow[t]{2}{*}{ DLQI } & $\mathrm{M}$ & $4.67^{\mathrm{a}}$ & $4.25^{\mathrm{a}}$ & $4.54^{\mathrm{a}}$ & $4.04^{\mathrm{a}}$ & $2.79^{\mathrm{a}}$ & $3.61^{\mathrm{a}}$ \\
\hline & $\mathrm{SD}$ & 4.83 & 4.58 & 4.70 & 3.5 & 2.95 & 3.53 \\
\hline \multirow[t]{2}{*}{ Anxiety } & M & $4.25^{\mathrm{b}}$ & $4.08^{b}$ & $4.21^{\mathrm{b}}$ & $6.64^{\mathrm{a}}$ & $5.61^{\mathrm{ab}}$ & $6.29^{\mathrm{a}}$ \\
\hline & $\mathrm{SD}$ & 2.88 & 3.83 & 2.5 & 3.09 & 3.15 & 4.03 \\
\hline \multirow[t]{2}{*}{ Depression } & M & $3.71^{\mathrm{a}}$ & $3.58^{\mathrm{a}}$ & $3.75^{\mathrm{a}}$ & $5.07^{\mathrm{a}}$ & $4.75_{\mathrm{a}}$ & $4.54^{\mathrm{a}}$ \\
\hline & SD & 2.39 & 2.45 & 2.49 & 2.91 & 2.72 & 3.38 \\
\hline \multirow[t]{2}{*}{ PASI } & M & $0.79^{\mathrm{ab}}$ & $0.71^{\mathrm{b}}$ & $0.67^{\mathrm{b}}$ & $1.11^{\mathrm{a}}$ & $0.86^{\mathrm{b}}$ & $0.65^{\mathrm{b}}$ \\
\hline & $\mathrm{SD}$ & 0.59 & 0.55 & 0.56 & 0.74 & 0.65 & 0.68 \\
\hline
\end{tabular}

T1, initial screening; T2, end of therapy; T3, follow-up; FDLQI, family dermatology life quality index; M, mean; SD, standard deviation; PASI, psoriasis area severity index. Superscript letters represent the pairwise differences according to t-test (alpha level $=0.05$ ) for each factor.

Table 2. Pair-wise Pearson correlation for anxiety, depression, family dermatology life quality index and psoriasis area severity index.

\begin{tabular}{lllll}
\hline & PASI & DLQI & Anxiety & Depression \\
\hline PASI & & & & \\
\hline DLQI & 0.38 & & & \\
\hline Anxiety & 0.33 & 0.42 & 0.50 & 0.04 \\
\hline Depression & 0.21 & 0.13 & 0.13 & \\
\hline FDLQI & 0.15 & 0.11 & & \\
\hline
\end{tabular}

PASI, psoriasis area severity index; DLQI, family dermatology life quality index; FDLQI, family DLQI. Italics represent the pairwise correlation with $\mathrm{P}<0.05$. 
chodynamic theoretical approach in a focus group setting involving psoriatic patients, focusing on the effects of the participation on their caregivers. The study had an exploratory nature, given the limited period of the intervention (6 Focus Group meetings) and the limited number of participants (52 patients, 41 caregivers). Indeed, the effects of the intervention were not evident on the patients themselves. The experimental group was characterized by initial higher anxiety than the control, which did not further worsen over time, possibly thanks to the participation in the group, but any conclusion on this should be taken carefully. Possibly, anxiety, depression and quality of life of our patients is grounded in very deep and long-standing causes that cannot be modified with only 6 meetings. More important to the scope of the present study is the indirect effect of a psychological intervention for caregivers, on which we can draw some preliminary considerations.

The caregivers of the patients who agreed to participate in the meetings presented an initial quality of life more compromised than the caregivers of the group of patients who did not agree to participate in the Focus Group. Possibly, patients (and their corresponding caregivers) who accepted to be involved in the focus groups were more in contact with their suffering linked to the pathology. These results are also in line both with the systemic approach according to which there is an interconnection between people belonging to the same affective network (Haley \& Hoffman, 1967) - and with studies focusing on the impact between psoriatic pathology and their impact on their family members' QoL (Eghlileb et al., 2007; Kross, 2015). Furthermore, the results of our study show that the caregivers of the patients participating in the Focus Group Meetings reported a better quality of life after the meetings $(\mathrm{M}=2.59$; $\mathrm{SD}=2.61)$ than before $(\mathrm{M}=3.82 ; \mathrm{SD}=3.33)$, which also further improved at the follow up $(\mathrm{M}=2.23 ; \mathrm{SD}=2.64)$. This improvement over time was independent from the seriousness of the pathology of their relatives. This is in line with some literature (Richards et al., 2002; Eghlileb et al., 2007), but not with others (Tadros et al., 2011). Further studies (possibly meta-analytic) are needed to explore the relationship between caregivers' burden and patients' disease severity. We assume that the participation of patients in the Focus groups affected their caregivers in a direct (rather than mediated) way. Specifically, the intervention may have benefited the caregivers because it alleviated them from their responsibility towards the patients. Knowing that their cared ones were regularly meeting a psychologist may have alleviated caregivers' preoccupation associated with their role in the pathology. Arguably, the group represents a third party between patient and caregiver (Anzieu, 1993), which takes off the 'weight' of the pathology, eventually acting as a containment barrier of the consequences of the patient's pathology on the caregivers. This is in line with the results reported in their meta-analysis by Del-Pino-Casado and colleagues (2018), according to which the perceived social support is even more important than the actual social support for caregivers' burden.

These results seem to go in the direction of what Basra et al. (2008) and Eghlilib et al. (2007) postulated with the concept of 'The Greater Patient' to describe 'the immediate social grouping of family and partner who are also affected by an individual having skin disease' (Eghlilib et al., 2007, p. 1250). The authors emphasize the importance of considering the patient not only according to their individual characteristics, but also in relation to the people who take care of them.

The study presents some key limitations that should be taken into account. First of all, the intervention is limited in duration. Six Focus Group meetings is a short intervention for a psychodynamic approach, and this may explain why we could not observe any clear effect on patients' wellbeing. A second important limit is represented by the sample size, involving only 52 patients, 41 caregivers. Future studies are therefore needed to replicate the present findings. A third important element is represented by the enrolling procedure. Patients were assigned to either the control or experimental group and then respectively offered to participate in either: i) the focus groups and the questionnaires' completion; or ii) in the questionnaires' completion only. This may be related to the initial difference between the two groups in terms of psychological distress. The experimental participants have voluntarily accepted the offer to participate in a highly demanding and time-consuming focus group, whereas control participants accepted a less demanding procedure, namely filling in some questionnaire. It is possible that experimental patients were on average more motivated by higher awareness of their psychological distress. Future studies should include interventions with psoriatic patients and specific focus groups with their caregivers in order to investigate the specific factors related to the mutual relationship between emotional characteristics and FDLQI of caregivers, patients' well-being and psychological support.

\section{Conclusions}

The present study shows encouraging results about the relationship between caregivers' well-being (FDLQI) and supportive interventions for psoriatic patients. Since the intervention failed to exert any observable effect on patients in the considered timeframe, and given the absence of relation between patients' and caregivers' wellbeing, we cannot draw solid conclusions about the eventual indirect effect of psychological support to patients on caregivers. However, the pattern supports the hypothesis that caregivers benefit in a direct way from the psychological interventions provided to patients, shedding light on the importance of alleviating caregivers from the responsibility of the psychological wellbeing of the patients. 


\section{References}

Anzieu, D. (1993). L'Io-pelle familiare e gruppale. Interazioni, 7, 9-17.

Ak, M., Haciomeroglu, B., Turan, Y., Lapsekili, N., Doruk, A., Bozkurt, A., \& Akar, A. (2012). Temperament and character properties of male psoriasis patients. Journal of Health Psychology, 17(5), 774-781. doi: 10.1177/1359105311423863

Baranzoni, N., Scalone, L., Mantovani, LG., De Portu, S., Monzini, MS., \& Giannetti, A. (2007). Validazione della versione Italiana dell'Indice Dermatologico della Qualità di Vita. Giornale Italiano di Dermatologia e Venereologia, 142(3), 209-214.

Basra, M. K., Fenech, R., Gatt, R. M., Salek, M. S., \& Finlay, A. Y. (2008). The dermatology life quality index: a comprehensive review of validation data and clinical results. British Journal of Dermatology, 159, 997-1035. doi: 10.1111/j. 1365-2133.2008.08832

Basra, M. K., \& Finlay, A.Y. (2007). The family impact of skin diseases: the greater patient concept. British Journal of Dermatology, 156(5), 929-937. doi: 10.1111/j.1365-2133.2007. 07794.

Bundy, C., Pinder, B., Bucci, S., Reeves, D., Griffiths, CE., \& Tarrier, N. (2013). A novel, webbased, psychological intervention for people with psoriasis: the electronic Targeted Intervention for Psoriasis (eTIPs) study. British Journal of Dermatology, 169, 329-336. doi: 10.1111/bjd.12350.

Chamoun, A., Goudetsidis, L., Poot, F., Bourdeaud'hui, F., \& Titeca, G. (2015). Psoriasis and depression. Revue Medicale de Bruxelles, 36(1), 23-28.

Connor, CJ., Liu, V., \& Fiedorowicz, JG. (2015). Exploring the physiological link between psoriasis and mood disorders. Dermatology Research Practice, 15, 1-12. doi: 10.1155/ 2015/409637

Costantini, M., Musso, M., Viterbori, P. , Bonci, F., Del Mastro, L., Garrone, O., Venturini, M. \& Morasso, G. (1999). Detecting psychological distress in cancer patients: validity of the Italian version of the hospital anxiety and depression scale. Support Care Cancer, 7(3), 121-127.

Del-Pino-Casado, R., Frías-Osuna, A., Palomino-Moral, P. A., Ruzafa-Martínez, M., \& Ramos-Morcillo, A. J. (2018). Social support and subjective burden in caregivers of adults and older adults: a meta-analysis. PLoS One, 13(1): e0189874. doi: 10.1371/journal.pone.0189874

Eghlileb, A. M., Davies, E. E., \& Finlay, A. Y. (2007). Psoriasis has a major secondary impact on the lives of family members and partners. Brithsh Journal of Dermatology, 156(6), 1245-1250. doi:10.1111/j.1365-2133.2007.07881

Fabbrini, G., Abbruzzese, G., Barone, P., Antonini, A., Tinazzi, M., Castegnaro, G., Rizzoli, S., Morisky, D. E., Lessi, P.,\& Ceravolo, R. (2013). Adherence to anti-Parkinson drug therapy in the "REASON" sample of Italian patients with Parkinson's disease: the linguistic validation of the Italian version of the 'Morisky Medical Adherence scale-8 items'; On behalf of the REASON study group. Neurology Science, 34, 2015-2022. doi: 10.1007/s10072-013-1438-1

Feldman, S. R., Fleischer, A. B., Reboussin, D. M., Rapp, S. R., Exum, M. L., Clark, A. R., \& Nurre, L. (1996). The self-administered psoriasis area and severity index is valid and reliable. Journal of Investigation in Dermatology, 106, 83-86.

Finlay, A.Y., \& Khan, G.K. (1994). Dermatology life quality index (DLQI) - a simple practical measure for routine clinical use. Clinical and Experimental Dermatology 19 (3), 210-216.

Fortune, D., Richards, H. L., Main, C. J., \& Griffiths, C. E. (2000). Pathological worrying, illness perceptions and disease severity in patients with psoriasis. British Journal of Health Psychology, 5(1), 71-82. doi:10.1348/ 135910700168775

Goldberg, A. R., \& Rickler, S. R. (2011). The role of family caregiver for people with chronic illness. Medicine and Health (Rhode Island), 94(2), 41-42.

Grapsa, E., Pantelias, K., Ntenta, E., Pipili, C., Kiousi, E., Samartzi, M., Karagiannis, S., \& Heras. P. (2014). Caregivers' experience in patients with chronic diseases. Social Work in Health Care, 53(7), 670-678. doi: 10.1080/00981389.2014.925998

Haley, J., \& Hoffman, L. (1967). Techniques of family therapy. New York, NY: Basic Books.

Kabat-Zinn, J., Wheeler, E., Light, T., Skillings, A., Scharf, M. J., Cropley, T. G., Hosmer, D., \& Bernhard, J. D. (1998). Influence of a mindfulness meditation based stress reduction intervention on rates of skin clearing in patients with moderate to severe psoriasis undergoing phototherapy (UVB) and photochemotherapy (PUVA). Psychosomatic Medicine, 60, 625-632.

Kreft, S., Kreft, M., Resman, A., Marko, P., \& Kreft, K. Z. (2006). Computer-aided measurement of psoriatic lesion area in a multicenter clinical trial-comparison to physician's estimations. Journal of Dermatological Sciences, 44, 21-27.

Kross, E. K. (2015). The importance of caregivers outcomes after critical illness. Critial Care Medicine, 43 (5), 11491150. doi:10.1097/CCM.0000000000000910

Lin V. W. (2012). Tough-skinned kids: identifying psychosocial effects of psoriasis and helping pediatric patients and families cope. Journal of Pediatric Nursing, 27(5), 563-572. doi: 10.1016/j.pedn.2011.10.003

Mackenzie, K. R. (1995). Effective use of group therapy in managed care. Washington, DC: American Psychiatric Press.

Manolache, L., Petrescu- Seceleanu, D. \& Benea, A. (2010). Life events involvement in psoriasis onset/recurrence. International Journal of Dermatology, 49, 636-641. doi: 10.1111/j.1365-4632.2009.04367

Martín-Brufau, R., Romero-Brufau, S., Martín-Gorgojo, A., Brufau Redondo, C., Corbalan, J., \& Ulnik, J. (2015). Psoriasis lesions are associated with specific types of emotions. Emotional profile in psoriasis. European Journal of Dermatology, 25, 329-34. doi: 10.1684/ejd.2015.2577

Michalek I. M., Loring, B., \& John, S. M. (2017). A systematic review of worldwide epidemiology of psoriasis. Journal of the European Academy of Dermatology and Venereology, 31 (2), 205-212. doi: 10.1111/jdv.13854

Molina-Leyva, A., Caparros-delMoral, I., Ruiz-Carrascosa, J. C., Naranjo-Sintes, R., \& Jimenez-Moleon, J. J. (2015). Elevated prevalence of Type $\mathrm{D}$ (distressed) personality in moderate to severe psoriasis is associated with mood status and quality of life impairment: a comparative pilot study. Journal of the European Academy of Dermatology and Venereology, 29, 1710-1717. doi: 10.1111/jdv.12960

Morisky, D. E., Green, L. W., \& Levine, D. M. (1986). Concurrent and predictive validity of a self-reported measure of medication adherence. Medical Care, 67-74.

Nestle, F. O., Kaplan, D. H., \& Barker, J. (2009). Psoriasis. New 
England Journal of Medicine, 36, 1496-1509. doi: 10.1056/ NEJMra0804595

Petraškienè, R., Valiukevičienė, S., \& Macijauskienė, J. (2016). Associations of the quality of life and psychoemotional state with sociodemographic factors in patients with psoriasis. Medicina (Kaunas), 52(4), 238-243. doi: 10.1016/j.medici. 2016.07.001

Remröd, C., Sjöström, K., \& Svensson, Å. (2015). Subjective stress reactivity in psoriasis- a cross sectional study of associated psychological traits. Dermatology, 15(2), 6. doi:10.1186/s12895-015-0026

Richards, H. L., Chong, S. L. P., Mason, D. L., \& Griffiths, C. E. (2002). The impact of psoriasis on healthy partners of patients with psoriasis. British Journal of Psoriasis, 147(62), 40 (Abstr).

Salman, A., Yucelten, A. D., Sarac, E., Saricam, M. H., \& Perdahli-Fis, N. (2018). Impact of psoriasis in the quality of life of children, adolescents and their families: a cross-sectional study. Brasilian Dermatology, 93(6), 819-823. doi: 10.1590/abd1806-4841.20186981

Sampogna, F., Tabolli, S., Di Pietro, C., Castiglia, D., Zambruno, G., Abeni, D. (2013). The evaluation of family impact of recessive dystrophic epidermolysis bullosa using the italian version of the family dermatology life quality index. Journal of the European Academy of Dermatology and Venerology, 27(9), 1, 151-155. doi: 10.111/j. 1468308.2012.04682.X
Schwartz, J., Evers, A. W. M., Bundy, C., Kimball, A. B. (2016). Getting under the skin: report from the International Psoriasis Council Workshop on the role of stress in psoriasis. Frontiers in Psychology, 7, 87. doi: 10.3389/fpsyg.2016.00087

Sobell, J. M., Foley, P., Toth, D., Mrowietz, U., Girolomoni, G., Goncalves, J., Day, R. M., Chen R., \& Yosipovitch, G. (2016), Effects of apremilast on pruritus and skin discomfort/pain correlate with improvements in quality of life in patients with moderate to severe plaque psoriasis. Acta Dermato-Venereologica, 96(4), 514-520. doi: 10.2340/ 00015555-2360

Tadros, A., Vergou, T., Stratigos, A. J., Tzavara, C., Hletsos, M., Katsambas, A., \& Antoniou, C. (2011). Psoriasis: is it the tip of the iceberg for the quality of life of patients and their families?. Journal of the European Academy of Dermatology and Venereology, 25 (11), 1282-1287. doi: 10.1111/j.14683083.2010.03965

Yalom, I., \& Leszcz, M. (2005). The Theory and Practice of Group Psychotherapy (5th ed.). New York, NY: Basic Books.

Zeng, J., Luo, S., Huang, Y., \& Lu Q. (2017). Critical role of environmental factors in the pathogenesis of psoriasis. Journal of Dermatology, 44(8), 863-872. doi: 10.1111/13468138.13806

Zigmond, A. S., \& Snaith, R. P. (1983). The hospital anxiety and depression scale. Acta Psychiatrica Scandinavica, 67(6), 361-370. 